\title{
KESIAPSIAGAAN MASYARAKAT TERHADAP BENCANA TSUNAMI DI KELURAHAN PASIR PUTIH, MANOKWARI
}

\author{
Erikha Maurizka Mayzarah $^{\text {a }}$, Philipus Samuel Max Batmomolin ${ }^{\mathrm{b}}$
}

${ }^{a}$ Universitas Papua, Jl. Gunung Salju Amban, Manokwari 91911, Indonesia

${ }^{b}$ Universitas Papua, Jl. Gunung Salju Amban, Manokwari 91911, Indonesia

\section{INFO ARTIKEL}

\section{Status artikel:}

Diterima: 15-02-2021

Disetujui: 01-03-2021

Tersedia online: 04-03-2021

\section{Kata kunci:}

Community, Disaster, Preparedness, Tsunami

\section{Penulis korespondensi:}

Erikha Maurizka Mayzarah

UNIPA, Manokwari, Indonesia

Email: e.mayzarah@unipa.ac.id DOI: 10.34312 /jgej.v2i1.9956

Copyright $@ 2021$ The Authors

\section{ABSTRACT}

Manokwari Regency is one of the districts in West Papua Province which has the potential for moderate to high Tsunami vulnerability. One of the vulnerable districts is East Manokwari District. Potential disaster vulnerability in an area should be followed by community preparedness. This is because when a disaster occurs, the community already understands what steps to take. This study aims to determine the level of overall preparedness of the community in Pasirido Village, East Manokwari District. This research was conducted for one month in January 2021 in Pasirido Village, East Manokwari District, Manokwari Regency. This research uses quantitative methods. The sample was determined using the method of puposive sampling with the category of the head of the family and has lived for 10 years in Kampung Pasirido so that a total sample of 30 respondents. Data collection was carried out by distributing questionnaires and interviews to respondents. The questionnaire used is a standard from LIPI-UNESCO / ISDR 2006 with parameters of knowledge and attitude (KA), emergency response plan (EP), disaster warning (WS), and resource mobilization (RMC). The results showed that the level of community preparedness on the parameters of knowledge and attitude was mostly in the very ready category of $67 \%$. The level of community preparedness in the parameters of the emergency response plan was mostly in the very ready category of $60 \%$. The level of community preparedness for disaster warning parameters in the very ready category was $93 \%$. The level of community preparedness on the parameter of resource mobilization was mostly in the ready category of $80 \%$. Based on these four categories, overall community preparedness for flood disasters is included in the very ready category of $77 \%$. The recommendation of this study is the need to increase community preparedness by conducting training to simulations from related agencies to the community. This is so that all people in Pasirido Village are in the category of being very prepared to face the Tsunami disaster.

\section{ABSTRAK}

Kabupaten Manokwari merupakan salah satu kabupaten di Provinsi Papua Barat yang memiliki potensi rentan Tsunami yang sedang hingga tinggi. Salah satu kecamatan yang rentan adalah Kecamatan Manokwari Timur. Potensi kerentanan bencana pada suatu wilayah seharusnya diikuti dengan kesiapsiagaan masyarakatnya. Hal ini dikarenakan agar ketika bencana terjadi, maka masyarakat tersebut sudah paham akan langkah langkah apa saja yang harus dilakukan. Penelitian ini bertujuan untuk mengetahui tingkat kesiapsiagaan secara keseluruhan masyarakat di Kampung Pasirido, Kecamatan Manokwari Timur. Penelitian ini dilakukan selama satu bulan pada Januari 2021 di Kampung Pasirido Kecamatan Manokwari Timur, Kabupaten Manokwari. Penelitian ini menggunakan metode Kuantitatif. Penentuan sampel menggunakan metode Puposive Sampling dengan kategori kepala keluarga dan telah tinggal selama 10 tahun di Kampung Pasirido sehingga didapatkan total sampel sebanyak 30 responden. Pengumpulan data dilakukan dengan cara penyebaran kuesioner dan wawancara pada responden. Kuesioner yang digunakan merupakan standar baku dari LIPI-UNESCO/ISDR 2006 dengan parameter pengetahuan dan sikap (KA), rencana tanggap darurat (EP), peringatan bencana (WS), dan mobilisasi sumber daya (RMC). Hasil penelitian menunjukkan tingkat kesiapsiagaan masyarakat pada parameter pengetahuan dan sikap sebagian besar dengan kategori sangat siap sebesar $67 \%$. Tingkat kesiapsiagaan masyarakat pada parameter rencana tanggap darurat sebagian besar dengan kategori sangat siap sebesar $60 \%$. Tingkat kesiapsiagaan masyarakat pada parameter peringatan bencana dengan kategori sangat siap sebesar 93\%. Tingkat kesiapsiagaan masyarakat pada parameter mobilisasi sumberdaya sebagian besar 
dengan kategori siap sebesar 80\%. Berdasarkan keempat kategori ini maka kesiapsiagaan masyarakat secara keseluruhan terhadap bencana banjir termasuk pada kategori sangat siap sebesar $77 \%$. Rekomendasi dari penelitian ini adalah perlunya peningkatan peningkatan kesiapsiagaan masyarakat dengan melakukan pelatihan hingga simulasi dari instansi yang terkait kepada masyarakat. Hal ini agar seluruh masyarakat di Kampung Pasirido termasuk pada kategori sangat siap menghadapi bencana Tsunami.

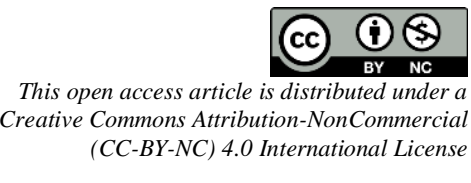

\section{Pendahuluan}

Indonesia merupakan salah satu negara yang terletak pada kawasan cincin api pasifik. Selain itu, secara geografis Indonesia merupakan batas pertemuan antar lempeng Samudera Pasifik, Lempeng Eurasia dan Lempeng Indo-Australia (Setyaningrum, Niken; Setyorini, 2020). Hal ini menyebabkan Indonesia menjadi negara yang memiliki potensi bencana hidrometerologis maupun geologis yang tinggi. Bencana geologis yang cukup sering terjadi berupa Gempa Bumi, Tsunami, dan Tanah Longsor.

Provinsi Papua Barat berpotensi tingkat tinggi terhadap bencana tsunami. Sebagian pulau bahkan dalam kuantitas besar masyarakat tinggal dan hidup di daerah pantai dan pesisir (Kobi \& Hendra, 2020) Dimana sebagian besar pantai yang mengelilingi Papua Barat berpotensi terjadi bencana tsunami. Mengingat bahwa sumber gempa penyebab bencana tsunami dapat berasal dari perairan Papua Barat maupun dari perairan lainnya. Gelombang tsunami yang pernah terjadi di daerah Manokwari setinggi 1 hingga 5 meter. Tingkat bahaya tsunami yang tinggi dengan persebaran tidak terlalu luas terdapat di sepanjang pantai Provinsi Papua Barat bagian barat (Kab. Teluk Wondama, Kabupaten Manokwari) dan Provinsi Papua Barat bagian utara (Kota Manokwari, Kabupaten Manokwari dan Kabupaten Sorong). Kabupaten Manokwari berpotensi bencana tinggi tsunami meskipun persebaran yang relatif terbatas karena topografi yang relatif tinggi .Kecamatan yang memiliki area berisiko tinggi di Kabupaten ini yaitu Kecamatan Manokwari Timur sebesar 60,68\% (Naryanto, 2019).

Tsunami merupakan rangkaian gelombang laut yang menjalar dengan kecepatan tinggi (Badan Nasional Penanggulangan Bencana (BNPB), 2012). Kejadian tsunami di Indonesia sebagian besar disebabkan oleh gempabumi. Sebagian besar penyebab tsunami dikarenakan oleh gempa yang menimbulkan longsoran bawah laut. Dimana posisi kejadian longsoran sulit ditemukan sehingga banyak yang tidak menyadari kejadian ikutan tersebut (Naryanto, 2019). Dampak dari bencana tsunami sangatlah besar karena dapat menimbulkan kematian, kehilangan dan kerusakan sarana prasarana serta mengganggu keadaan psikologi. Faktor utama timbulnya banyak korban adalah faktor manusia yang kekurangan pengetahuan dan kesiapsiagaan dalam mengantisipasi dan menghadapi bencana tsunami (Satria \& Sari, 2017). Perlu diketahui bahwa pengetahuan, sikap dan kepedulian siap siaga dalam menghadapi bencana merupakan hal utama dalam kesiapsiagaan (Setyaningrum, Niken; Setyorini, 2020)

Kesiapsiagaan merupakan upaya dan kegiatan yang dilakukan secara cepat dan efektif sebelum terjadi bencana alam, saat bencana dan setelah bencana. Upaya ini sangat diperlukan masyarakat untuk mengurangi dampak dari bencana alam (Hidayati, 2008). Penelitian tentang kesiapsiagaan masyarakat dalam menghadapi bencana sangat dibutuhkan untuk manajemen bencana pada masa datang. Manajemen bencana adalah upaya sistematis dan komprehensif untuk menanggulangi semua kejadian bencana secara cepat, tepat, dan akurat dalam meminimalisir korban dan kerugian yang ditimbulkan (Ramli, 2010).

Beberapa daerah dari Kecamatan Manokwari Timur terletak pada pesisir pantai Papua Barat. Salah satu Kelurahan yang terletak dipesisir pantai yaitu Kelurahan Pasir Putih. Kondisi ini menyebabkan Kelurahan Pasir putih masuk pada kategori area yang berisiko tinggi terhadap bencana Tsunami. Area dengan kategori tersebut seharusnya memiliki masyarakat yang memiliki pengetahuan dan kesiapsiagaan terhadap bencana tsunami. Dimana, hal ini didapatkan dari pendidikan formal maupun informal masyarakat. Salah satu pendidikan yang dapat meningkatkan kesiapsiagaan masyarakat melalui pelatihan maupun simulasi yang dilakukan oleh dinas terkait. Akan tetapi, hingga saat ini belum dilakukan penelitian terkait seberapa siapsiaga masyarakat terhadap bencana tsunami sehingga belum dapat diketahui langkah apa yang harus dilakukan pemerintah untuk manajemen bencana pada masa datang. 
Berdasarkan latar belakang diatas, maka tujuan dari penelitian ini adalah mengetahui tingkat kesiapsiagaan secara keseluruhan masyarakat di Kampung Pasirido, Kecamatan Manokwari Timur.

\section{Metode}

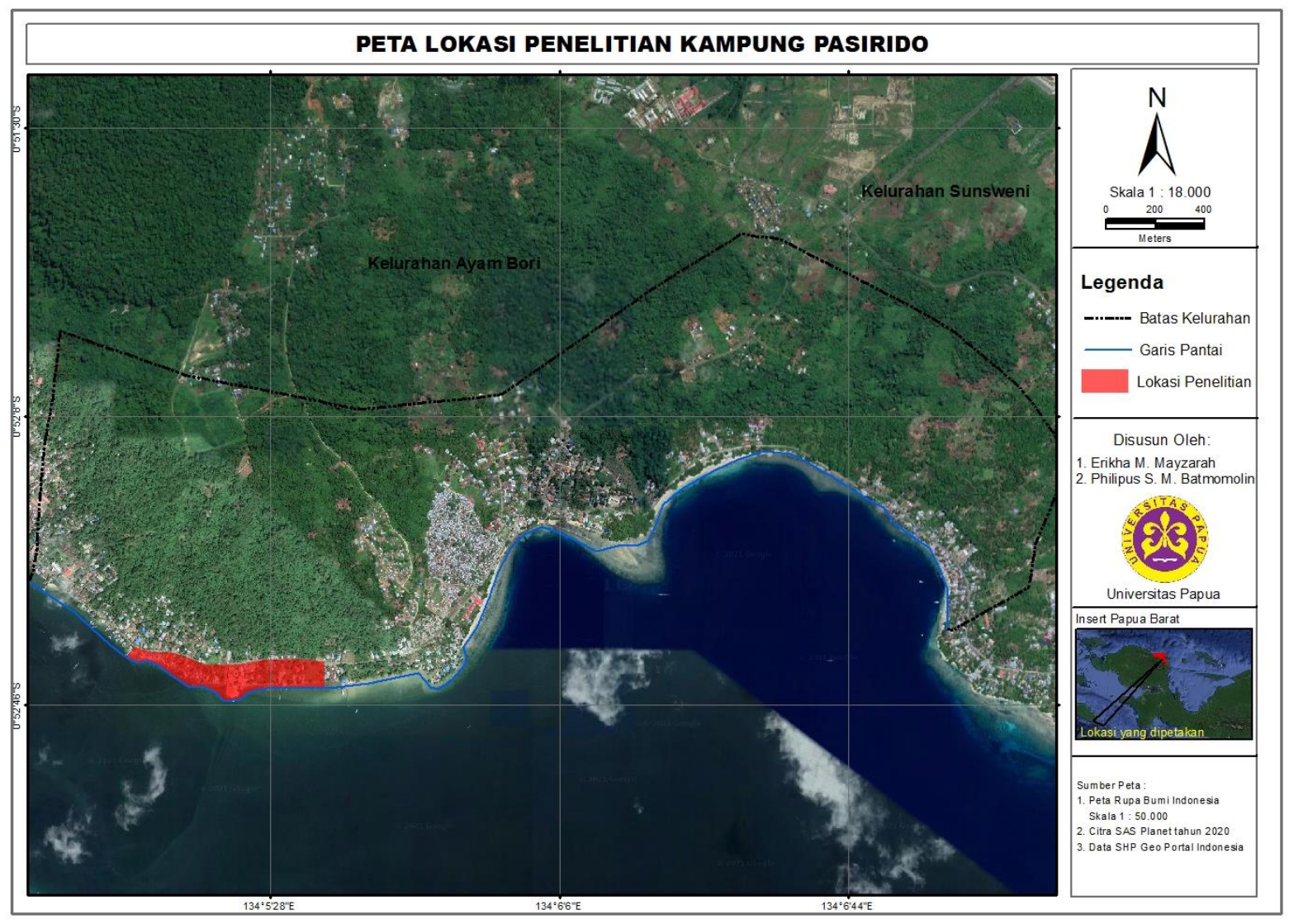

\section{Gambar 1. Peta Lokasi Penelitian}

Penelitian ini dilakukan pada Kampung Pasirido, Kelurahan Pasir Putih, Kecamatan Manokwari Timur, Kabupaten Manokwari (Gambar 1). Dimana penelitian ini dilaksanakan selama 1 bulan pada Januari 2021.

\subsection{Teknik Pengambilan Sampel}

Populasi penelitian ini merupakan seluruh Kepala Keluarga di Kelurahan Pasirido sedangkan sampelnya berasal dari Masyarakat yang berada di RT 1 Kampung Pasirido. Hal ini dijadikan sampel karena lokasi pemukiman terletak pada pesisir pantai dan masuk pada kawasan Bahaya Tsunami dengan kelas tinggi sesuai dengan INA-Risk BNPB. Sampel pada penelitian ini dipilih berdasarkan metode puposive sampling dengan kriteria yaitu Kepala Keluarga dan telah tinggal selama 10 tahun. Total sampel penelitian sebanyak 30 orang responden.

\subsection{Metode Pengumpulan Data}

Penelitian ini bersifat deskriptif dengan penggunaan metode kuantitatif. Pengumpulan data menggunakan penyebaran kuesioner dan wawancara kepada responden.Kuesioner yang digunakan untuk mengukur kesiapsiagaan masyarakat terhadap bencana tsunami menggunakan standar baku dari LIPI-UNESCO/ISDR 2006 dengan parameter pengetahuan dan sikap (KA), rencana tanggap darurat (EP), peringatan bencana (WS), dan mobilisasi sumber daya (RMC).

\subsection{Analisis Data}

Analisis data dari angket kuesioner yang telah dibagikan akan dilakukan skoring kemudian menghitung indeks kesiapsiagaan. Rumus yang digunakan sebagai berikut (LIPI-UNESCO/ISDR, 2006): 


$$
\text { Indeks }=\frac{\text { Total Skor riil Parameter }}{\text { Skor Maksimum parameter }} \times 100 \%
$$

Setelah didapatkan Indeks Kesiapsiagaan setiap parameter maka dilakukan penghitungan indeks $\mathrm{s}$ keseluruhan dengan rumus sebagai berikut (LIPI-UNESCO/ISDR, 2006):

Indeks Total $=0,83 \times$ Indeks $K A+0,08 \times$ Indeks $E P+0,04 \times$ Indeks WS $+0,04 \times$ Indeks RMC

Selanjutnya, hasil dari indeks kesiapsiagaan diklasifikasikan sesuai dengan tabel 1. Berikut tabel kategori kesiapsiagaan:

Tabel 1. Kategori Indeks Kesiapsiagaan

\begin{tabular}{cl}
\hline Nilai Indeks & Kategori \\
\hline $80-100$ & Sangat Siap \\
\hline $65-79$ & Siap \\
\hline $55-64$ & Hampir Siap \\
\hline $40-54$ & Kurang Siap \\
\hline $0-39$ & Belum Siap \\
\hline
\end{tabular}

Sumber: (LIPI-UNESCO/ISDR, 2006)

\section{Hasil dan Pembahasan}

Hasil penelitian tentang kesiapsiagaan masyarakat terhadap bencana Tsunami di Kampung Pasirido dapat dijelaskan sebagai berikut:

Tabel 2. Kesiapsiagaan berdasarkan parameter Pengetahuan dan Sikap masyarakat Kampung Pasirido

\begin{tabular}{ccc}
\hline Kategori & Frekuensi (F) & Persentase (\%) \\
\hline Sangat Siap & 20 & 67 \\
\hline Siap & 6 & 20 \\
\hline Hampir Siap & 4 & 13 \\
\hline Kurang Siap & - & - \\
\hline Belum Siap & - & - \\
\hline
\end{tabular}

Sumber: Hasil Analisis Data Penulis, 2021

Berdasarkan tabel 2, diketahui bahwa tingkat kesiapsiagaan berdasarkan parameter pengetahuan dan sikap termasuk dalam kategori sangat siap sebesar $67 \%$, siap sebesar $20 \%$ dan hampir siap sebesar $13 \%$. Pengetahuan merupakan faktor kunci untuk kesiapsiagaan sebuah bencana pada masyarakat (Hidayati, 2008). Dimana parameter ini biasanya mempengaruhi sikap perilaku masyarakat untuk siap siaga dalam mengantisipasi dan menghadapi bencana. Untuk itu, maka diperlukan pendidikan terkait bencana. Pendidikan ini tidak hanya dengan menggunakan buku teks tetapi juga melalui pembelajaran praktis dan pengalaman. pengetahuan yang didapat harus diterapkan menjadi sikap pada kehidupan sehari hari (Pascapurnama et al., 2018). Pengetahuan dipengaruhi oleh faktor umur, pendidikan, sosial dan ekonomi. Dimana semakin tingginya pendidikan manusia maka semakin tinggi pula pengetahuannya (Kim \& Kang, 2010). Hal ini sejalan dengan penelitian (Baker et al., 2012) yang menyebutkan bahwa lulusan perguruna tinggi dianggap lebih siap menghadapi bencana. Berdasarkan hal ini maka pengetahuan dianggap sebagai dasar untuk melakukan kegiatan yang benar untuk mengantisipasi datangnya bencana tsunami. 
Tabel 3. Kesiapsiagaan berdasarkan parameter Rencana Tanggap darurat masyarakat Kampung Pasirido

\begin{tabular}{ccc}
\hline Kategori & Frekuensi (F) & Persentase (\%) \\
\hline Sangat Siap & 18 & 60 \\
\hline Siap & 8 & 27 \\
\hline Hampir Siap & 4 & 13 \\
\hline Kurang Siap & - & - \\
\hline Belum Siap & - & - \\
\hline
\end{tabular}

Sumber: Hasil Analisis Data Penulis, 2021

Berdasarkan tabel 3, diketahui bahwa tingkat kesiapsiagaan berdasarkan parameter rencana tanggap darurat termasuk dalam kategori Sangat siap dsebesar 60\%, siap sebesar 27\% dan hampir siap sebesar 13\%. Parameter rencana tanggap darurat menjadi faktor penting dalam kesiapsiagaan karena berkaitan dengan evakuasi, pertolongan pertama dan penyelamatan. Tujuan dari perencanaan kesiapsiagaan adalah untuk memastikan ketepatan dan tindakan efektif jika terjadi bencana dengan mengintegrasikan dan mempertimbangkan sistem penanggulangan bencana diwilayah dan disesuaikan dengan kondisi lokal (Afrida \& Manawanui, 2018). Bentuk atau produk dari rencana ini adalah dokumen, seperti kesiapan rencana, rencana darurat / kontingensi, dan dokumen kesiapsiagaan terkait, termasuk sistem peringatan dini yang disusun dengan mempertimbangkan ketelitian dan kontekstualitas lokal. Berdasarkan observasi di lapangan untuk Rencana tanggap darurat sudah ada jalur evakuasi yang dipasang demi keselamatan warga sekitar. Adanya rambu-rambu untuk mengurangi resiko hilangnya nyawa pada saat terjadi bencana. Tanda mitigasinya berupa rambu jalur evakuasi, rambu berkumpul, rambu bahaya dan lain sebagainya. Perlu diketahui pula bahwa pengetahuan dan sikap masyarakat sangat berkaitan dengan parameter ini. Hal itu disebabkan karena pengetahuan dan sikap dapat meningkatkan rencana tanggap darurat dalam menghadapi bencana tsunami.

Tabel 4. Kesiapsiagaan berdasarkan parameter Peringatan Bencana masyarakat Kampung Pasirido

\begin{tabular}{ccc}
\hline Kategori & Frekuensi (F) & Persentase (\%) \\
\hline Sangat Siap & 28 & 93 \\
\hline Siap & 2 & 7 \\
\hline Hampir Siap & - & - \\
\hline Kurang Siap & - & - \\
\hline Belum Siap & - & - \\
\hline
\end{tabular}

\section{Sumber: Hasil Analisis Data Penulis, 2021}

Berdasarkan tabel 4, diketahui bahwa tingkat kesiapsiagaan berdasarkan parameter peringatan bencana termasuk dalam kategori Sangat siap sebesar 93\% dan siap sebesar 7\%. Peringatan bencana meliputi tanda peringatan dan distribusi informasi kepada masyarakat tentang informasi akan terjadi bencana. Dengan adanya parameter ini, masyarakat diharapkan melakukan tindakan yang tepat untuk mengurangi korban jiwa maupun kerusakan. Untuk itu, diperlukan peningkatan tentang pengetahuan sistem peringatan bencana yang bertujuan mengantisipasi lebih dini dampak tsunami (Rachmalia \& Astuti, 2012). Peningkatan ini dapat dilakukan dengan cara latihan dan simulasi langkah-langkah yang perlu dilakukan apabila mendengar peringatan, cara menyelamatkan diri dalam waktu tertentu. Latihan dan simulasi harus sesuai dengan lokasi dimana masyarakat sedang berada saat terjadinya peringatan. Sikap dan perilaku masyarakat yang paham dengan proses mitigasi dan evakuasi menjadi cerminan dari sistem peringatan bencana yang baik. Hal ini akan mengakibatkan masyarakat lebih siap dalam mengantisipasi dan menghadapi bencana Tsunami (BNPB; BPS; UNFPA, 2013) 
Tabel 5. Kesiapsiagaan berdasarkan parameter Mobilisasi Sumber Daya masyarakat Kampung Pasirido

\begin{tabular}{ccc}
\hline Kategori & Frekuensi (F) & Persentase (\%) \\
\hline Sangat Siap & 2 & 7 \\
\hline Siap & 24 & 80 \\
\hline Hampir Siap & 4 & 13 \\
\hline Kurang Siap & - & - \\
\hline Belum Siap & - & - \\
\hline
\end{tabular}

Sumber: Hasil Analisis Data Penulis, 2021

Berdasarkan tabel 5, diketahui bahwa tingkat kesiapsiagaan berdasarkan parameter mobilisasi sumber daya termasuk dalam kategori sangat siap sebesar 7\%, siap sebesar $80 \%$ dan hampir siap sebesar $13 \%$. Kemampuan Mobilisasi sumder daya menjadi potensi yang dapat mendukung atau sebaliknya menjadi kendala dalam kesiapsiagaan mengantisipasi tsunami. Dimana mobilisasi yang baik dapat meningkatkan kesiapsiagaan masyarakat saat terjadi bencana. Bentuk sumber daya yang perlu diperhatikan juga yaitu sarana dan prasarana serta pendanaan untuk mendukung kesiapsiagaan. Oleh karena itu, parameter ini menjadi faktor yang krusial (Hidayati, 2008). Berdasarkan hasil survei di lapangan menunjukkan bahwa sebagian besar masyarakat belum memiliki tabungan darurat jika terjadi bencana. Menurut (Erlia et al., 2017) hal ini dipengaruhi oleh pendidikan dan penghasilan yang masih rendah. Selain masyarakat, pemerintahpun wajib memberikan fasilitas mobilisasi sumber daya seperti dana khusus jika terjadi bencana.

Tabel 6. Kesiapsiagaan Bencana Tsunami pada Masyarakat Kampung Pasirido

\begin{tabular}{ccc}
\hline Kategori & Frekuensi (F) & Persentase (\%) \\
\hline Sangat Siap & 23 & 77 \\
\hline Siap & 4 & 13 \\
\hline Hampir Siap & 3 & 10 \\
\hline Kurang Siap & - & - \\
\hline Belum Siap & - & - \\
\hline
\end{tabular}

Sumber: Hasil Analisis Data Penulis, 2021

Berdasarkan tabel 6, diketahui bahwa kesiapsiagaan bencana tsunami pada masyarakat Kampung Pasirido termasuk pada kategori Sangat siap sebesar 77\%. Penelitian ini sejalan dengan penelitian (Herdwiyanti \& Sudaryono, 2012) yang menyebutkan kesiapsiagaan masyarakat yang tepat dan efektif dalam menghadapi bencana dapat dilihat dari sejauh mana mereka dapat tanggap dalam merespon bencana. Hal ini dapat diketahui dari hasil wawancara dan jawaban kuesioner tentang aspek kesiapsiagaan dalam menghadapi bencana tsunami.

\section{Kesimpulan}

Berdasarkan hasil penelitian dari penilaian parameter pengetahuan dan sikap, Kebijakan, rencana tanggap, peringatan bencana dan mobilisasi sumber daya maka dapat disimpulkan tingkat kesiapsiagaan masyarakat pada parameter pengetahuan dan sikap sebagian besar dengan kategori sangat siap sebesar 67\%. Tingkat kesiapsiagaan masyarakat pada parameter rencana tanggap darurat sebagian besar dengan kategori sangat siap sebesar $60 \%$. Tingkat kesiapsiagaan masyarakat pada parameter peringatan bencana dengan kategori sangat siap sebesar $93 \%$. Tingkat kesiapsiagaan masyarakat pada parameter mobilisasi sumberdaya sebagian besar dengan kategori siap sebesar $80 \%$. Berdasarkan keempat kategori ini maka kesiapsiagaan masyarakat secara keseluruhan terhadap bencana banjir termasuk pada kategori sangat siap sebesar $77 \%$. 
Rekomendasi dari penelitian ini adalah perlunya peningkatan peningkatan kesiapsiagaan masyarakat dengan melakukan pelatihan hingga simulasi dari instansi yang terkait kepada masyarakat. Hal ini agar seluruh masyarakat di Kampung Pasirido termasuk pada kategori sangat siap menghadapi bencana Tsunami.

\section{Ucapan Terima Kasih}

Penulis mengucapkan terima kasih kepada ketua RT 1 Kampung Pasirido dan Kepala Lurah Pasir Putih, Kecamatan Manokwari Timur, Kabupaten Manokwari yang telah memberikan izin melakukan wawancara kepada masyarakatnya. Selain itu, ucapan terima kasih juga kepada masyarakat RT 1 Kampung Pasirido yang telah bersedia menjadi responden untuk penelitian ini.

\section{Referensi}

Afrida, Y., \& Manawanui, R. (2018). School Community Preparedness in Reducing The Risk of Earthquake and Tsunami Disasters in Pesisir Selatan Regency. Sumatra Journal of Disaster, Geography and Geography Education, 2(1), 24. https://doi.org/10.24036/sjdgge.v2i1.129

Badan Nasional Penanggulangan Bencana (BNPB). (2012). Dokumenn Kajian Risiko Bencana Kabupaten Manokwari Papua Barat. In PT Amythas.

Baker, N. D., Feldman, M. S., \& Lowerson, V. (2012). Workingthroughdisaster:reestablishingmentalhealthcare after hurricane katrina. Disaster Medicine and Public Health Preparedness, 6(3), 311-315. https://doi.org/10.1001/dmp.2012.12

BNPB; BPS; UNFPA. (2013). Kesiapsiagaan menghadapi bencana Kota Padang 2013. Pilot Survei Pengetahuan, Sikap dan Perilaku. Pusdatin Humas BNPB.

Erlia, D., Kumalawati, R., \& Aristin, N. (2017). Analisis Kesiapsiagaan Masyarakat dan Pemerintah Menghadapi Bencana Banjir di Kecamatan Martapura Barat Kabupaten Banjar. Jurnal Pendidikan Geografi, 4(3), 15-24. http://dx.doi.org/10.20527/jpg.v4i3.3525

Herdwiyanti, F., \& Sudaryono. (2012). Perbedaan Kesiapsiagaan Menghadapi Bencana Ditinjau dari Tingkat Self-Efficacy pada Anak Usia Sekolah Dasar di Daerah Dampak Bencana Gunung Kelud. Jurnal Psikologi Kepribadian Dan Sosial, 1(03), 136-141.

Hidayati, D. (2008). Kesiapsiagaan Masyarakat: Paradigma Baru Pengelolaan Bencana Alam (Community Preparedness: New Paradigm in Natural Disaster Management). Jurnal Kependudukan Indonesia, 3(1), 69-84.

Kim, Y. C., \& Kang, J. (2010). Communication, neighbourhood belonging and household hurricane preparedness. Disasters, 34(2), 470-488. https://doi.org/10.1111/j.1467-7717.2009.01138.x

Kobi, W., \& Hendra, H. (2020). KAJIAN GEOGRAFI EKONOMI: STUDI KASUS KONDISI SOSIAL EKONOMI MASYARAKAT SUKU BAJO DI POPAYATO, GORONTALO. JAMBURA GEO EDUCATION JOURNAL, 1(1), 16-25.https://doi.org/10.34312/jgej.v1i1.4637

LIPI-UNESCO/ISDR. (2006). Kajian Kesiapsiagaan Masyarakat dalam Mengantisipasi Bencana Gempa Bumi dan Tsunami. Deputi Pengetahuan Kebumian LIPI.

Naryanto, H. S. (2019). Analisis Bahaya, Kerentanan Dan Risiko Bencana Tsunami Di Provinsi Papua Barat. Jurnal Alami: Jurnal Teknologi Reduksi Risiko Bencana, $3(1), \quad 10$. https://doi.org/10.29122/alami.v3i1.3399

Pascapurnama, D. N., Murakami, A., Chagan-Yasutan, H., Hattori, T., Sasaki, H., \& Egawa, S. (2018). Integrated health education in disaster risk reduction: Lesson learned from disease outbreak following natural disasters in Indonesia. International Journal of Disaster Risk Reduction, 29(March), 94-102. https://doi.org/10.1016/j.ijdrr.2017.07.013

Rachmalia, \& Astuti, P. (2012). PENGETAHUAN KESIAPSIAGAAN TSUNAMI PADA MASYARAKAT TEUPAH BARAT, KABUPATEN SIMEULUE Knowledge of Tsunami Preparedness in the 
Communities of Teupah Barat of Simeulue Regency. Idea Nursing Journal, 3(3), 39-49.

Ramli, S. (2010). Pedoman Praktis Manajemen Bencana. Dian Rakyat.

Satria, B., \& Sari, M. (2017). Tingkat Resiliensi Masyarakat Di Area Rawan Bencana. Idea Nursing Journal, $8(2), 30-34$.

Setyaningrum, Niken; Setyorini, A. (2020). Tingkat Kesiapsiagaan Kepala Keluarga dalam Menghadapi Bencana Gempa Bumi di Kecamatan Pleret dan Piyungan Kabupaten Bantul. Jurnal Kesehatan AlIrsyad, 13(1), 84-92. https://doi.org/10.36760/jka.v13i1.61 